\title{
Notas sobre a Apropriação de uma Etnografia: o caso da Polícia Militar de São Paulo
}

\author{
Piero de Camargo Leirner
}

\begin{abstract}
resumo Este texto pretende relatar o caso da apropriação de uma etnografia que fiz sobre o exército brasileiro por parte da polícia militar de São Paulo. Inesperadamente, fui convidado a assistir uma representação de cadetes da PM sobre elementos desta, quando se colocou a idéia de que a etnografia acabara por servir como uma espécie de "manual de instruçóes" sobre certos valores a serem defendidos pela corporação. Tal apropriação me levou a pensar como duas instituiçóes com uma natureza táo semelhante - exército e PM - puderam ter leituras tão diferenciadas de um mesmo texto. Trata-se, assim, de pensar a natureza dessas instituiçôes no Estado, percebendo os matizes que não necessariamente podem ser empacotados na embalagem comum da idéia de "monopólio legítimo da violência”.
\end{abstract}

palavras-chave Etnografia. Exército. Polícia. Estado.

\section{Introdução}

Embora o tema das "apropriações de etnografias" por parte de grupos seja algo já explorado metodologicamente (Gonçalves da Silva 1991), é notável que ele tenha sido pouco estendido para a reflexáo sobre a natureza dos grupos que então se utilizam desses meios. É um dado mais ou menos "natural" que tais esforços etnográficos muitas vezes se destinem aos grupos tidos como "periféricos" (Durham 1988; Beviláqua \& Leirner 2000), movimento que inclusive culminou numa tendência, a essas alturas já consolidada (e pra lá de dis- cutida...), de grupos "minoritários" ou "não hegemônicos" produzirem seus "antropólogos orgânicos” e suas respectivas etnografias.

Também é notável que boa parte da discussão que envolve os "limites de uma auto-antropologia" (Strathern 1987; Rapport \& Overing 2000: 18-28), raras vezes tenha se voltado a pensar sobre grupos ou agentes táo ou mais "centrais" ou "hegemônicos" que os próprios antropólogos ${ }^{1}$ - uma exceção é Latour (e.g. Latour \& Woolgar 1979). E, menos ainda, fala-se de casos em que tais grupos ou atores fazem uso ou se "apropriam" de etnografias. Podemos, obviamente, sempre supor que certos temas nas ciências sociais podem vir a ser mais ou menos "interessados" - que uma sociologia da arte sirva para legitimar elites emergentes, que uma "antropologia da antropologia" venha a se esforçar para redefinir o diagrama de forças no campo acadêmico, que exista aquilo que Bourdieu chamou de "ciência de Estado" (Bourdieu 1996); enfim, que uma elite possa até "comprar” um trabalho acadêmico, é algo possível, senão mesmo esperável. No entanto, à par desses caminhos, também pode haver a possibilidade de apropriaçóes inusitadas de etnografias: aquelas que absolutamente fogem do controle dos antropólogos a partir do momento em que seus textos são publicados.

Pois bem. O presente texto trata da descrição da (1) apropriação involuntária de uma etnografia (2) por parte de um grupo que pode

1. E “centrais" para os próprios antropólogos, diga-se de passagem. 
ser tomado como "central": oficiais da Polícia Militar do Estado de São Paulo². Uma ressalva, antes de tudo: é verdade que tal grupo difere bem no seu habitus (Bourdieu 1977) daqueles, por exemplo, que poderíamos chamar de "elites" da nossa sociedade ${ }^{3}$. Mas, também é verdade, os oficiais da PM estão bem longe de se considerarem equivalentes sociológicos de operários, camponeses, mulheres pobres da periferia das grandes cidades brasileiras - aproveitando o sentido assumido em Peirano (1996) - assim como tais segmentos, também, certamente não os enxergam assim.

$\mathrm{O}$ inusitado da situaçáo me parece residir no fato de que tal "grupo" - e provisoriamente vamos tratá-los como um grupo ${ }^{4}$ - definitivamente náo necessita, à primeira vista pelo menos, de legitimaçóes como aquelas que antropólogos podem, por ou sem querer, oferecer (cf. também Sá 2002, que tem uma boa discussão sobre pesquisa de campo com a PM do Ceará, e Castro 1990, que inaugura a análise antropológica de militares). Bem, talvez nada disso seja uma questáo de necessidade; então, digamos de outro jeito: tal grupo dificilmente toma gosto por descrições etnográficas, quanto mais a seu próprio respeito (pelo menos foi isso que aprendi com seus colegas do exército, em campo). A questáo que me intriga: por

2. Tive, como se verá adiante, contato com um grupo de oficiais, e não com todos oficiais da PM de SP. No, entanto, dada a oficialidade do evento, e as características hierárquicas da corporação (ver discussão infra), pode-se de certo modo tomar a parte pelo todo.

3. Talvez sejam, antes, um "grupo" a serviço do "centro", mas nem por isso menos imbricado a este.

4. Trata-se de uma corporação que tem mecanismos intensos de socialização que visam, antes de mais nada, inculcar em seus membros a idéia de que se trata de um grupo distinto do resto da sociedade, seguindo assim prescriçōes bastante semelhantes àquelas que Castro (1990) observou entre os cadetes e que observei (Leirner 1997a) entre oficiais do exército. Voltaremos a isso. que então tive uma etnografia apropriada por tal grupo, que passou a usá-la como modelo para pensar em princípios que estruturam seu próprio mundo? E mais: por que fui chamado à Corporação para ver o resultado dessa apropriação? O presente texto trata, assim, desses mecanismos de transferência que ocorreram a partir de uma série de eventos que envolvem uma etnografia.Vamos, entáo, aos fatos.

\section{Uma seqüência de eventos}

Os fatos que me fizeram tomar ciência de tal apropriaçáo remetem a fins de 2002. Fui convidado por uma oficial da PM de Sáo Paulo a comparecer à Academia do Barro Branco, onde se formam os futuros Oficiais da corporação, para uma solenidade que em parte se basearia em dados retirados de minha etnografia sobre o Exército Brasileiro (EB), publicada no ano de 1997, e que então havia sido incorporada no currículo de formaçáo dos cadetes da $\mathrm{PM}^{5}$. Soube, posteriormente, que tal incorporaçáo deveu-se ao contato de uma Oficial-Instrutora com o livro, a partir de uma indicaçáo de uma colega antropóloga que então ministrava a ela um curso de pós-graduação lato sensu na Escola de Sociologia e Política em São Paulo. Tratavase para mim de uma incógnita, pois fatos que remetiam há anos atrás me levavam a crer que minha etnografia náo tinha sido bem recebida em meios militares. Cabe assim esclarecê-los.

Voltemos ao ano de 1995, quando estava para defender o mestrado que originaria tal publicação e me encontrava nos passos finais de elaboração da etnografia, mas ainda em contato bastante próximo com oficiais do exército.

5. Os cadetes da PM de SP entram para academia a partir de processo seletivo realizado pela FUVEST - a mesma que seleciona os alunos da USP. Trata-se, até o ano de 2005, de uma das três carreiras mais concorridas do vestibular em termos da relação candidato/ vaga. 
Numa história que só vale a pena delinear de forma bastante sintética ${ }^{6}$, entendi, após três anos do que considerava uma seqüência de tentativas frustradas de realizar uma determinada investigação com militares, que ao longo de meu contato com eles - períodos intermitentes que variaram de contatos de 1 dia a duas semanas, totalizando cerca de duas dúzias - havia sido colocado cara a cara com um princípio central de sua cosmologia (algo semelhante ao gado nuer, à bruxaria azande ou ao milho araweté) sem perceber. Tratava-se da hierarquia, um fato tão óbvio, tão onipresente na vida militar, que se apagou para o antropólogo e, também, para o nativo que gostaria de entender o que esse antropólogo gostaria mesmo de estudar.

Essa mesma hierarquia que náo via era o ponto que emperrava o que então buscava, a chance de sincronizar o pensamento militar com a questão amazônica a partir "de dentro". Tinha como resposta um certo silêncio sobre o assunto, em contrapartida com uma série de ensinamentos nativos sobre o "verdadeiro" ponto de vista (global, cosmológico, etc). Sinceramente, a princípio pouco dei bola sobre esse "ponto de vista”, que no meu entender descentrava a questão que gostaria de pesquisar. Contudo, incidentes em campo aos poucos foram revelando que a hierarquia era um fato que permeava não só as relaçôes e dimensões "internas" da vida militar como também suas classificações "externas", ou visão do "mundo exterior".

Bem, o resultado disso se expressa em duas teses sobre hierarquia militar, suas implicações para a construçáo do mundo interno e sua gramática no interior daquilo que posteriormente entendi ser um "sistema da guerra" (Leirner 2001). Tal ponto não vem ao caso; o que talvez interesse é o fato de que dizer que a hierarquia é um "fato social total" para os militares teve como contrapartida posterior um "fechamen-

6. Narrativas mais detalhadas dessa "pesquisa de campo"
estão em Leirner (1997a; 1997b). to" da instituição para futuras pesquisas. Jamais soube exatamente o porquê, embora tenha especulado bastante. Provavelmente, embora a hierarquia não constitua nenhum segredo (pelo contrário, usam e abusam dela), não se admite que ela seja o princípio de unificação do grupo - por paradoxal que pareça, o que separa, unifica... -, mas sim apenas a base para que outros princípios - honra, disciplina, amor à pátria, etc., que julguei como cimentos ideológicos do princípio hierárquico - tomados como as verdadeiras motivaçóes que unem o militar à corporação, venham se manifestar. Seria algo semelhante a tentar explicar a um trobriandês que o hau é a troca em operação, com todos os problemas que isso pode acarretar...

O fato é que à época também não dei bola a uma categoria que os nativos usavam de maneira insistente, mas que anos depois fez sentido. Diziam eles que tal país ou fulano era amigo ou inimigo do exército. Exatamente, trata-se de algo genérico o suficiente para dar conta de uma pessoa ou de uma nação. Percebi entáo que a inimizade era mais do que uma simples palavra, tratava-se de uma modalidade de relação ampla e profunda o suficiente para tratá-la com um grau de abstração maior do que o uso corriqueiro a princípio poderia sugerir. Sem maiores divagaçóes, imagino que ela pode ser tomada como base para pensar a guerra, digamos, em um sentido "antropológico"7: a guerra é uma relação, de inimizade, recíproca e generalizada.

Náo cabe aqui desdobrar os porquês e as conseqüências desse uso conceitual da guerra. Vale dizer por enquanto que alguém (do exérci-

7. Diferente portanto da noção usualmente citada nas ciências sociais, que aproveita a máxima de Clausewitz de que a "guerra é a continuação da política por outros meios”. Uma maior problematização sobre o conceito de guerra na própria antropologia, e de como ele se aproxima de uma idéia de política, está em Leirner (2001). 
to) me disse que havia deixado de ser um amigo do EB; isto é, no mínimo, para pensar o melhor, não me adeqüei ao plano que inicialmente era esperado para nossa relação, qual seja: tornarme uma espécie de elo de ligação entre militares e universidade, num momento em que essas eram extremamente rarefeitas (estamos falando de aproximadamente 1995, como relato em Leirner 1997b). Isso não aconteceu, tornei-me um antropólogo que os chamava de "nativos", e isso talvez não tenha agradado alguém...

Pois bem, vi-me aproximadamente 7 anos depois com um convite para comparecer, como amigo da PM de SP a uma solenidade, que prestaria uma pequena homenagem justamente baseada na mesma pesquisa que anos antes havia me colocado no ostracismo enquanto pesquisador daquele "objeto" (lembre-se aqui que ele tem bem mais poder para decidir quem vai e quem não vai pesquisá-lo). Fui, então.

Passei por um procedimento bastante conhecido. Alguém estava a minha espera, logo na entrada da Academia, esta sustentada por duas grandes pilastras marmorizadas em estilo que não me recordo se grego ou jônico. Tal pessoa me leva à responsável por toda operação - a instrutora que havia tido contato com meu livro - e esta me leva à sala do comandante. Este é um procedimento padrão em instituiçóes militares: um subordinado o recebe, transmite o convidado à parte responsável ou interessada, esta faz as vezes com um superior - dependendo da importância do convidado, é um alto superior ou alguém subalterno. No caso, fui primeiramente à sala de um responsável pelo curso e depois fomos todos à sala do comandante (cabe notar que nesse circuito sempre se passa por corredores, onde se é apresentado à maioria das pessoas por quem se passa, e a partir daí por ante-salas, onde um ajudante ou encarregado trata de anunciá-lo ao chefe de seção).

Quando conduzido à sala, notei uma reu- niáo, em que estavam presentes alguns comandantes de Armas: tropa de choque, polícia rodoviária, bombeiros, polícia, da própria Academia do Barro Branco, além de um juiz e, se não me engano, de um promotor de justiça. Com a cordialidade habitual que militares têm com seus amigos, fui muito bem recebido, elogiado, indagado sobre o que estava fazendo no momento, e, obviamente, prestado a ouvir uma conversa sobre a importância de iniciativas que visam reconhecer o "verdadeiro" lado de corporaçóes militares (isso também era uma prerrogativa para o $\mathrm{EB})$. Depois dessa rápida "sala de estar", todos nos dirigimos ao que interessava: uma sala, transformada em auditório, onde seria realizado o esperado evento.

Tratava-se de uma dramatização ou, quase dizendo assim, uma espécie de "psicodrama" da vida militar, baseada em meu livro. Era a reapresentação de uma encenação que ocorrera como trabalho de fim de curso de um grupo de cadetes, que havia sido muito elogiada e repercutira de forma muito positiva no comando da academia. Imaginei mesmo que se tratava de algo de proporçóes mais intensas do que antes esperava, uma vez que a essas alturas já sabia o que significava a presença de comandantes de Armas ou Tropas. O que aconteceu então?

À entrada, distribuíram-se crachás que ostentavam apenas as patentes - soldados, sargentos, coronéis, etc -, que se destinaram aos seus portadores de forma aleatória (o que gerou um certo constrangimento, pelo que pude perceber: um coronel recebeu a patente de "soldado" e deu uma risada nervosa; também recebi esta). Todos se sentaram, ocupando os cantos de uma sala de aproximadamente $80 \mathrm{~m}^{2}$, obedecendo à disposição hierárquica (dos crachás), como é de praxe nas corporaçóes militares: o mais graduado senta-se no centro, em oposição à porta, e os subalternos vão se distribuindo em ordem decrescente um a um, à direita e à esquerda de seu superior imediato, em forma respectiva. Ao 
meio das cadeiras, em posiçóes estratégicas de modo a preencher espaços simétricos da sala, estavam em pé pessoas vestindo um manto encapuzado e segurando velas, dando um certo tom de mistério e uma aura de religiosidade à cena.

Sentados todos e em silêncio, abre-se uma porta, onde um jovem aparentemente encena, sob o som de uma música (não me recordo agora, acho que era Beethoven), algo que representaria a série de etapas por que um cadete passa durante os anos de academia: a chegada assustado; os trotes; o companheirismo de turma; a rotina de estudos; o duro treinamento físico; a socializaçáo. Tal etapa durou algo como $5 \mathrm{mi}$ nutos. Foi o preparativo para o ápice: finalmente, quando a aluno está para sair da academia, é amarrado ao seu corpo, por uma corrente, duas colunas de mármore que replicam justamente aquelas que sustentam a entrada do saguão da Academia: tratava-se da miniatura batizada de... Hierarquia e Disciplina!

Eis que o jovem cadete entra na sala, arrastando as colunas com extrema dificuldade, simulando choro e sinais de forte emoção, aos gritos de frases como "não agüento mais", "não posso mais", "preciso desistir”. À chegada ao centro da sala, no momento mesmo em que ele ameaça livrar-se das correntes, os encapuzados que se situavam de pé pela sala retiram seus mantos, revelando que por baixo deles há um representante de cada comando: polícia rodoviária, choque, bombeiros, etc. Esses se dirigem ao jovem, seguram-no, erguem-no junto com as colunas, libertam-no das correntes, e o fazem perceber que, no fundo, essas colunas sustentam sua vida no interior da corporação (" e essas colunas são o meu alicerce daqui para a frente"...). Acaba a encenação.

Quando se acendeu a luz, percebi uma cena de comoção no ambiente; o que certamente me assustou, pois novamente me vi diante daquela situação que achei que essa história de hierarquia e disciplina tratava-se de uma grande ob- viedade. Mas náo era, de novo me enganei, e o pior, me enganei a partir de meu próprio trabalho! Todos se dispersaram, o circuito inverso se fez de novo: me dirigi à sala do comandante, ouvi agradecimentos pelos serviços prestados; desci às instalaçóes da academia, onde me foi colocado como "tudo nesse lugar é absolutamente igual lá no exército". Coloquei-me a pensar: se de fato é igual, por que tamanha diferença na recepção de minha etnografia? Como posso ser amigo aqui e inimigo lá?

\section{Conclusão, se é que é possível...}

De fato, responder essa pergunta só é plenamente possível em um tom algo especulativo. Prefiro enunciar uma pista, a partir de uma conversa que tive na saída da Academia. Percebi, passando pelo hall de entrada, que junto às colunas havia um panfleto, que justamente dizia algumas coisas do curso, e, mais especificamente, da disciplina cuja atividade que acabara de assistir. Uma coisa me chamou muito a atenção, uma transcrição de um trecho de meu livro, sem citação, mas que eu sabia ser um apud de um trecho selecionado da célebre "Introdução à Obra de Marcel Mauss", de C. Lévi-Strauss (1974 [1950]). Tratava-se do seguinte:

"Que o fato social é total não significa apenas que tudo o que é observado faz parte da observação, mas também, e principalmente, que em uma ciência em que o observador é da mesma natureza que seu objeto, o observador é, ele mesmo, parte de sua observação." (Lévi-Strauss 1974 [1950]: 16).

Por que aquela frase encontrava-se solta, em meio a outras como "Saber, Ética e Conduta"? Lembrei-me de que sempre vi coisas assim no $\mathrm{EB}$, frases pregadas em paredes, inscriçóes soltas na paisagem. Um ex-oficial me disse que isso 
era uma forma de pensamento mnemônico, princípios que se internalizam pela sua referência minimalista e auto-repetitiva. Suspeitei que aquela frase tinha a ver com alguma "regra de torção" do sentido original e que a relação observador-observado poderia estar sendo modulada como "amigo-inimigo". Não resisti à pergunta: "se vocês são iguais ao $\mathrm{EB}$, então

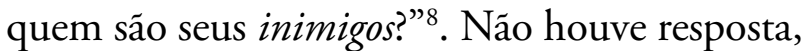
porque simplesmente não teria como haver. Sabia que a lógica da inimizade generalizada, para um exército, leva à idéia limite de que enfim todos os outros exércitos são inimigos potenciais, por isso algo que sempre era me dito: "Piero, estamos em guerra, pois estamos dissuadindo o inimigo".

Bem, é verdade que a polícia pode alegar que está dissuadindo o crime, mas o fato é que os exércitos têm consciência de quem e como são seus inimigos - e não é à toa que são todos iguais em sua gramática interna (Leirner 2001). Quanto à polícia, fica uma incógnita. Definitivamente o crime - e o criminoso - são "diferentes" e algo etéreos; tudo leva a crer que de fato há uma certa confusão entre o que é amigo e o que é inimigo numa PM, e aí a idéia de que o observado faz parte da observação (coisa que confunde a linearidade de qualquer sistema de informaçóes...!) começou a fazer mais sentido. Bem, mas para voltarmos ao início, é preciso ver o que essas noçóes, amigo/ inimigo, observador/ observado, podem dizer sobre a natureza desse grupo e sua "apropriação" da etnografia.

Tenho aqui duas coisas a dizer, para finalizar o texto: 1: se não se trata de uma minoria cuja etnografia pode "servir" como instrumento de legitimação, também não se trata de uma elite que pode colecionar mais essa

8. Se o leitor tiver curiosidade, basta entrar no sítio da APMBB e ver como ela se assemelha a uma típica academia militar. Entre as suas atividades, inclusive, há a de "defesa territorial". http://www.polmil.sp.gov. br/unidades/apmbb/. mercadoria como estratégia de distinção, no seu mundo extremamente competitivo, até porque aqui não há competição, lembre-se que é um monopólio. 2: também não se tratou, por isso mesmo, de uma visão "exótica" para o próprio grupo: em algo houve o que poderíamos chamar de uma apropriaçáo como "reavaliação funcional das categorias" (Sahlins 1990): o conteúdo da etnografia foi absorvido e domesticado, transformado no interior da corporação.

Por que então diferentemente do exército? Aqui só me resta um palpite: o EB, assim como qualquer outro exército, é a corporação armada para o exterior: a interpretação do antropólogo tem de tudo para ser vista como um horizonte a ser, se for, absorvido "de fora", trata-se de uma opinião alienígena. No caso da PM, sua posição voltada para o interior da sociedade que a gesta, permite que de dentro se coloquem as percepçóes exteriores... Embora sejam duas instituições-espelho, a única coisa que posso concluir, em antropologuês, é que se trata de afins. Fica, assim, um palpite, baseado numa velha dumontiana: afim de afim é consangüíneo, e assim me situo...

\section{Notes about an appropriation: how São Paulo's Police Force viewed a Bra- zilian Army's ethnography.}

abstract This article aims to show a case of my Brazilian Army's ethnography and its appropriation by the São Paulo's Police Force. Unexpectedly, I was invited to attend to a presentation of cadets about their own life in the military academy, when it was said that my ethnography was used as a kind of "instruction's manual" on their values, moral and institutional behavior. Such reading of my ethnography lead to a reflection on the nature of these two State's Institutions - Police and Army -, based on the fact that both had different interpretations: positive in the first case, negative on the second. Never- 
theless, in one hand, they seem to realize themselves as institutions of the same kind, with common vales and organizational systems. In other hand, the relations that they establish with the "encompassing world" shows us that they can't just be classified as deploy of the State's "monopoly on the legitimate use of physical force".

keywords Ethnography. Army. Police. State.

\section{Referências bibliográficas}

BEVILÁQUA, Ciméa; LEIRNER, Piero de Camargo. 2000. "Notas sobre a Análise Antropológica de Setores do Estado Brasileiro". Revista de Antropologia, 43 (2): 105-140.

BOURDIEU, Pierre. 1977. Outline of a Theory of Practice. Cambridge: C.U.P.

1996. "Espíritos de Estado: gênese e estrutura do campo burocrático". In: Razôes Práticas. Campinas: Papirus.

CASTRO, Celso. 1990. O Espirito Militar: Um Estudo de Antropologia Social na Academia Militar das Agulhas Negras. Rio de Janeiro: Jorge Zahar Editor.

DURHAM, Eunice. 1988. "A pesquisa antropológica com populaçóes urbanas: problemas e perspectivas", In R. Cardoso (org.), A aventura antropológica. Rio de Janeiro: Paz e Terra.

GONÇALVES DA SILVA, Vagner. 1991. "A Crítica Antropológica Pós-Moderna e a Construção Textual da Etnografia Religiosa Afro-Brasileira". Cadernos de Campo. 1: 47 - 60.

LATOUR, Bruno; WOOLGAR, S. 1979. Laboratory Life: the social construction of scientific facts. London:
Sage.

LEIRNER, Piero de Camargo. 1997a. Meia-Volta, Volver: um estudo antropológico sobre a hierarquia militar". Rio de Janeiro: FGV/Fapesp.

1997b. "A Pesquisa de Campo com Militares: algumas questôes metodológicas". Revista Brasileira de Ciências Sociais, No 34, São Paulo: Anpocs. 2001. O Sistema da Guerra: uma leitura antropológica dos exércitos modernos. Tese de Doutorado. Sáo Paulo: DA/FFLCH/USP.

LÉVI-STRAUSS, Claude. [1950]. "Introdução à Obra de Marcel Mauss", In: M. Mauss, Sociologia e Antropologia. 2Vols. São Paulo: EPU/Edusp, 1974.

PEIRANO, Mariza. 1996. A favor da etnografia. Rio de Janeiro: Relume-Dumará.

RAPPORT, Nigel; OVERING, Joanna. 2000. Social and Cultural Anthropology: the key concepts. London: Routledge.

SÁ, Leonardo Damasceno de. 2002. Os Filhos do Estado. Rio de Janeiro: Relume-Dumará.

STRATHERN, Marilyn. 1987. "The Limits of Autoanthropology". In: A. Jackson (ed.) Anthropology at Home. London: Routledge.

SAHLINS, Marshall David. 1990. Ilhas de História. Rio de Janeiro: Jorge Zahar Editor.

\section{Nota}

Uma primeira versão deste texto foi apresentada na VI RAM, no grupo "Antropologia do Estado", coordenado por mim e Ciméa Beviláqua. Aos seus participantes agradeço as sugestôes e críticas. Aproveito também para agradecer o gentil estímulo dos editores de Cadernos de Campo para enviar um artigo para este número.

\section{autor Piero de Camargo Leirner}

Professor do Departamento de Ciências Sociais / UFSCar

Doutor em Antropologia Social / USP

Editou a Cadernos de Campo nos 02, 04 e 05/06

Recebido em 25/05/2006

Aceito para publicação em 25/06/2006 